\title{
Türkiye’ de Marmara Bölgesinde Elektronik Sektöründe Faaliyet Gösteren Firmaların Çalışanlarının Dünya Klasmanında Güvenlik Algı Düzeylerinin Ölçülmesi Üzerine Bir Araştırma
}

\author{
Ezgi Tunçer ${ }^{*}$, Reşit Erçetin ${ }^{2}$ \\ 1 * İstanbul Aydın Üniversitesi, İş Sağlığı ve Güvenliği Enstitüsü, İş Sağlığı ve Güvenliği Anabilim Dalı, İstanbul, Türkiye, (ORCID: 0000-0002-8006-3823), \\ ezgituncer@stu.aydin.edu.tr \\ 2* İstanbul Aydın Üniversitesi, İş Sağlığı ve Güvenliği Enstitüsü, İş Sağlığı ve Güvenliği Anabilim Dalı, İstanbul, Türkiye (ORCID: 0000-0003-0432-6393), \\ resitercetin@aydin.edu.tr
}

(İlk Geliş Tarihi 3 Mayıs 2021 ve Kabul Tarihi 24 Temmuz 2021)

(DOI: 10.31590 /ejosat.931704)

ATIF/REFERENCE: Tunçer, E., Erçetin, R. (2021). Türkiye' de Marmara Bölgesinde Elektronik Sektöründe Faaliyet Gösteren Firmaların Çalışanlarının Dünya Klasmanında Güvenlik Algı Düzeylerinin Ölçülmesi Üzerine Bir Araştırma. Avrupa Bilim ve Teknoloji Dergisi, (25), 531-541.

\section{Öz}

Sanayinin gelişmesi işe bağlı yaralanma ve kazalardaki, işle ilgili mesleki hastalıklardaki artışı beraberinde getirmiştir. Kazaların sosyal ve ekonomik boyutları devlet, firmalar ve çalışanlar için kaygıya neden olmaktadır. Güvenlik kültürü, liderlik, güvenlik planı ve güvenlik performansı, işyerlerinde yaralanma ve kazaların olmaması amacı ile birtakım fayda sağlayacak uygulamalardan birkaçıdır. Son zamanlarda literatür araştırmaları doğrultusunda bunların doğrudan yada dolaylı olarak işletmelerin Dünya Klasmanında İş Sağlığı ve Güvenliği (DKG) uygulamaları ile ilişkili olduğunu söyleyebiliriz. Bu nedenle, bu çalışmada son zamanlarda literatürdeki çalışmalar üzerinden gidilerek belirlenen anket uygulaması ile Türkiye’de Marmara Bölgesi’nde Elektronik Sektöründe faaliyet gösteren firmaların çalışanlarının Dünya Klasmanında İş Sağlığı ve Güvenliği (DKG) algı seviyesini ölçmeye yönelik bir araştırma hedeflenmektedir. Verilerin analiz edilmesi sonucunda elde edilen bulgular, frekans dağılımı, güvenirlik analizi, ki kare testi, t-testi, korelasyon ve regresyon analizi kullanılarak değerlendirilmiştir.

Anahtar Kelimeler: Dünya Klasmanında İSG, Liderlik, Güvenlik Kültürü, Güvenlik Planı ve Güvenlik Performansı.

\section{A Research on Measuring The World Class Safety Perception Levels of The Employees of Companies Operating in The Electronics Sector in The Marmara Region of Turkey}

\begin{abstract}
The development of the industry has brought about an increase in work-related injuries and accidents and work-related occupational diseases. The social and economic dimensions of the accidents cause anxiety for the state, companies and employees. Safety culture, leadership, safety plan and safety performance are some of the applications that will provide some benefit in order to avoid injuries and accidents at workplaces. In line with recent literature studies, we can say that these are directly or indirectly related to the World Class Occupational Health and Safety (WCS) practices of businesses. This research measures the level of perception of safety and safety (WCS) of companies operating in the electronic sector located in Marmara region of Turkey by using a survey application determined by going through the literature that identifies the relationship between the WCS success of the safety culture, leadership, safety plan, safety performance. The findings obtained as a result of analyzing the data were evaluated using frequency distribution, reliability analysis, chi-square test, t-test, correlation and regression analysis.
\end{abstract}

Keywords: World Class Safety, Safety Culture, Leadership, Safety Plan and Safety Performance.

\footnotetext{
*Sorumlu Yazar: ezgituncer@stu.aydin.edu.tr
} 


\section{Giriş}

Sanayinin gelişmesi, artan rekabet koşullarında organizasyonların ayakta kalma çabalarının yanında birtakım problemleri de beraberinde getirmiştir. Bu problemlerin, işyerinde işin yürütüm koşullarından kaynaklanan meslek hastalıkları, yaralanma ya da ölümle sonuçlanan iş kazalarındaki artışa neden olduğunu söylemek mümkündür (Tufan ve Akın, 2021). Dünyada olduğu gibi ülkemizde de önemli bir sorunsal olan iş kazalarından kaynaklı çok sayıda kişinin sakat kaldığı ya da hayatını kaybettiği görülmektedir (Olcay ve diğ., 2021a). Gereksosyal, gerekse ekonomik kaygılar nedeniyle devlet, işveren ve çalışanlar için iş kazaları ve yaralanmaların önlenebilmesi çok büyük önem arz etmektedir. İş kazalarının oluşumunda en önemli unsur kişilerin tehlikeli davranışlarıdır (Sakallı A.E., 2019). Organizasyonlarda işle ilgili meslek hastalıklarının ve iş kazalarının önlenmesinde bir takım iş sağlığı ve güvenliği uygulamalarının yürütülmesi ile pozitif yönde katkılar sağlayabileceği bilinmektedir. Son yıllarda, iş kazalarına sebep olabilecek risklerin tespit edilmesi için sektörel bazda yürütülen çalışmalar önem taşımaktadır (Tufan Ö., 2020). Ayrıca literatürdeki araştırmalarında, çalışanların katılımı ile elde edilen verilerin istatistiksel analizlerinin gerçekleştirilmesi ve analiz sonuçlarının değerlendirilmesi üzerine yoğunlaştığı görülmektedir (Tufan ve Eren, 2019).

Firmalar küresel piyasa koşullarında rekabet edebilmek, işe bağlı yaralanma ve kazaların önlenmesi ve böylelikle performanslarını iyileştirmek için bir dizi üretim araçlarına ihtiyaç duymaktadır (Jahanzaib M., 2008) (Bozağaç İ., 2010). Bu uygulamalardan biri olan "Dünya Klasmanında Üretim” kavramı ilk olarak 1984'te Hayes ve Wheelwright'1n 'Rekabet Üstünlüğümüzü Geri Yükleme: Üretim Yoluyla Rekabet' adlı kitaplarında kullanılmıştır (Carlo F.D. and Simioli G.R., 2018) (Bozağaç İ., 2010). Schonberger 'sadelik dersleri' başlıklı çalışmasında bu yeni anlayışı ortaya koymuştur (Soloukdar A., 2011). Bu kavram üst yönetimin katılımını içermesinden dolayı yalın üretim, tam zamanında üretim (JIT), altı sigma, toplam kalite yönetimi (TQM) gibi kavramlara göre halen daha büyük avantajlar sunmaktadır (Geçgil E., 2018). Dünya Klasmanında İş Sağlığı ve Güvenliği (DKG) uygulamaları, güvenli çalışma ortamının oluşturulması ve sürekliliğinin sağlanmasına, üretim sürecinde kazayı oluşturan faktörlerin ve tehlikeli olayların azaltılmasına odaklanarak kazasız bir şekilde tamamlanması, kaza nedenlerinin analizlerinin yapılması ve benzer konularda alınabilecek ortak tedbirlerin genişletilmesi, ergonomi analizlerinin yapılarak olası meslek hastalıklarının önüne geçilmesi gibi planlı çalışmalardan oluşmaktadır (Tepekule E.T.,2015)(Ingle S., 1999). İşletme genelinde DKG'in sağlanabilmesi için çalışanların iş sağlığı ve güvenliği faaliyetlerine katılması, yönetiminde gerekli önlemleri alması ve katkı sağlayacak faaliyetleri desteklemesi gerekmektedir (Çögenli, M.Z ve Özer, M. 2017). Firmaların DKG uygulamaları dışarıdan bağımsız denetim kurumlarından gelen uzmanlar tarafından periyodik olarak denetlenmektedir (Geçgil E., 2018).

Hansen (2005) çalışmasında Amerikan Standart Safety\&Healthy ile benzer olarak başarılı bir dünya klasmanında iş sağlığı ve güvenliği için gerekli bileşenleri; Güvenlik Kültürü, Liderlik, Güvenlik Planı ve Güvenlik Performansı olarak dört element üzerinden tanımlamış ve nasıl olması gerektiğini gösteren karakteristik stratejiyi belirlemiştir. (Health \& Safety Executive, 2005) (Tepekule E.T.,2015). Güvenlik kültürü' terimi ilk olarak 1986 yılında Uluslararası Atom Enerjisi Ajansı'nın (IAEA) Uluslararası Nükleer Güvenlik Grubu (INSAG) (INSAG-
1) tarafindan Ukrayna' daki Çernobil Nükleer Reaktör kazasına ilişkin yapılan araştırmalar ve incelemeler sonucu hazırlanan bir raporda kullanılmıştır (Zopcuk O., 2015) (Kurtulmuş, G., 2019). Güvenlik kültürü, bir kuruluşun sağllk ve güvenlik yönetimine bağlılığı belirleyen bireysel ve grup değerlerinin, tutumlarının, algılarının, yetkinliklerinin ve davranış kalıplarının ürünü olarak tanımlanmaktadır (Cox, S.J., \& Cheyne, A.J.T. 2000) (Bergersen C.E.B.,2003). Güvenlik kültürü çalışma alanlarından kaynaklanabilecek kazaların önlenebilmesi, güvenli çalışma ortamlarının sağlanması için son yıllarda üzerinde önemle durulan bir kavramdır (Dursun S.,2013) (Aytaç S., 2011) (H. Gurbuz ve H. Ibrakovic, 2017). Liderlik kavramı son iki yüz yıldır yaygın kullanım alanı bulmuştur (Yang C.C. et all, 2009) (Uslu V.,2014). Literatürde pek çok liderlik türü tanımlanmış olup, dönüşümcü liderlik üzerine birçok çalışma yürütülmüştür. Birkaç yazar tarafından faydalı olduğu vurgulanmış ve güvenlik sonuçlarındaki değişiklikler gibi olayları açıklamak için kullanılmıştır (Caravello H.E., 2011) (Zia S.A., 2014). Güvenlik planında sıfır kaza amacına hizmet edebilmesi için planda acil durum planlamalarına da gereken önem verilmelidir. Böylelikle, oluşabilecek tehlike ve hasarlar minimize edilerek her türlü karşılaşılabilecek kötü sonuçtan koruma sağlanmış olur (Tepekule E.T.,2015). Güvenlik performansı kuruluşun etkinliğinin değerlendirilmesinde kullanılır (Uslu V.,2014). Güvenlik performansının ölçülmesinde, düşük kaza oranına sahip ve yüksek kaza oranına sahip firmaları karşılaştırma olanağı veren firmaların kaza istatistikleri, çalışanların kendi raporladıkları olay ve kazalar, çalışanların kendi raporladıkları güvenli davranışları, bir yönetici, amir veya düzenleyici tarafindan çalışana ait güvenlik performansı oranının belirlenmesi gibi dört farklı ölçüm aracı kullanılmaktadır. Uygun güvenlik performansı yönteminin seçilmesi, uygulanması ve elde edilen verilerin değerlendirilmesi gerekir (Kol İ., 2016).

Literatürde güvenlik kültürü, liderlik, güvenlik planı/programı ve güvenlik performansı ile bu dörtlünün aralarındaki olası etkinin (güvenlik kültürünün güvenlik davranışını nasıl etkilediği gibi) araştırıldığı çalışmalara rastlanıldığı ancak yeterli yoğunlukta olmadığı görülmektedir (Smith ve Wadsworth, 2007). Bu araştırma konularında çalışmaların sayısı uluslararası literatürde olduğu gibi ülkemizde de gittikçe artmaktadır. Bu alandaki önemli çalışmalardan bazıları Demirbilek'in (2005) tekstil endüstrisinde, Dursun (2011) ve Gürbüz'ün (2017) imalat endüstrisinde, yapmış oldukları araştırmalar oluşmaktadır. Literatürde güvenlik performansı ve güvenlik kültürü ilişkisini ele alan çalışmaların yeterli sayıda olmadığı, bu boyutların birbiri ile ilişkisini anlamada daha çok araştırmanın yapılması gerektiği söylenebilir (Dursun S., 2011) (Gürbüz H., 2017).

$\mathrm{Bu}$ araştırmaların doğrudan ya da dolaylı olarak organizasyonların Dünya Klasmanında İş Sağlığı ve Güvenliği (DKG) uygulamaları ve onun başarısı ile ilişkili olduğunu söylenebilmektedir (Wu, 2008). Wu (2008) çalışmasında güvenlik kültürü, liderliği ve güvenlik performansı arasındaki ilişkiyi belirlemek için genel bir model eksikliği olduğuna dikkati çekerek ve bunların aralarındaki olası ilişkiyi araştırmıştır. Ülkemizde yapılan birçok çalışmada Türkiye'de zayıf bir güvenlik kültürünün olduğu ifade edilmektedir (Olcay ve diğ., 2021b; Temur, 2019). Oluşan meslek hastalıkları ve özellikle yaşanan iş kazalarının azaltılabilmesi adına toplum olarak bilinçlenmek ve güvenlik kültürünün artırılıp, pozitif bir güvenlik algısı oluşturmak büyük önem taşımaktadır (Olcay, 2021). Liderlik davranışını destekleyerek, güvenlik kültürünü ve ekip üyelerinin güvenli davranışını etkileyerek, uzun vadede pozitif 
güvenlik kültürü oluşturabiliriz (Uslu V.,2014) (Akdeniz B., 2014).

Literatürde verilerin elde edilmesi amacıyla farklı alanlarda farklı organizasyonlarda uygulanmak üzere oluşturulmuş ölçeklerin mevcut olduğu söylenmektedir. $\mathrm{Bu}$ çalışmadada, güvenlik kültürü, liderlik, güvenlik planı ve güvenlik performansını ölçmek için literatür derlemelerinden elde edilen bir ölçüm kullanılmıştır.

\section{Materyal ve Metot}

\subsection{Araştırmanın Hipotezleri ve Kavramsal Modeli}

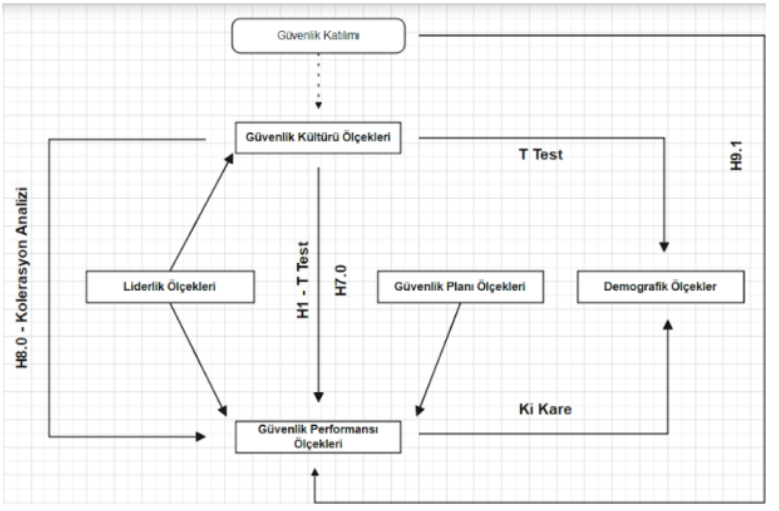

\section{Şekil 1: Araştırma Hipotezleri ve Kavramsal Modeli}

$\mathrm{Bu}$ araştırma kapsamında kurulan hipotezler Şekil 1'de görülmektedir. Bunlar;

H1.1: Güvenlik performansı değişkenlerinden çalışanların güvenli davranışları değişkeni ile her bir güvenlik kültürü değişkeni arasında istatistiksel olarak anlamlı bir farklılık var mı? H2.1: Demogrrafik değişkenlerden medeni durum değişkeni ile her bir güvenlik kültürü değişkenleri istatistiksel olarak anlamlı bir farklılık var mı?

H3.1: Güvenlik kültürü algı düzeyleri cinsiyet değişkeni ele alındığında cinsiyet bakımından çalışanların algı düzeyleri arasında istatistiksel olarak anlamlı bir farklılık var mı?

H4.1: Güvenlik kültürü değişkenlerinden yaş grubu boyutu ile her bir güvenlik kültürü değişkenleri arasında istatistiksel olarak anlamlı bir farklılık var mi?

H5.1: Demografik değişkenlerden öğrenim seviyesi değişkeninin her bir güvenlik kültürü değişkenleri arasında istatistiksel olarak anlamlı bir farklılık var mı?

H6.1: Demografik değişkenlerden işletmedeki konumu değişkeni ile her bir güvenlik kültürü değişkeni arasında istatistiksel olarak anlamlı bir farklılık var mi?

H7.1: Çalışma hayatında iş kazasına uğrama ile her bir güvenlik kültürü değişkeni arasında istatistiksel olarak anlamlı bir farklılık var $\mathrm{mi}$ ?

H8.1: Mevcut iş yerinde İş kazasına maruz kalanlar ile maruz kalmayanlar arasında istatistiksel olarak 'güvenlik farkındalığı ve yetkinliği, çalışanların katılımı ve kadercilik' boyutlarında anlamlı farklılıklar var $\mathrm{m}$ ?

H9.1: Güvenlik kültürü değişkenlerinden güvenlik eğitimi değişkeni ile güvenlik performansı değişkenlerinden güvenli davranış değişkeni arasında istatistiksel olarak anlamlı bir farklılık var mı?

\subsection{Araştırma Metodu}

\subsubsection{Araştırma Kapsamı, Örneklemi ve Veri Toplama Araçları}

Bu araştırmanın, Türkiye'de Marmara bölgesinde Elektronik sektöründe faaliyet gösteren firmaların çalışanlarına uygulanması kararlaştırılmıştır. Araştırma örneklemi, sadece beyaz yakalı çalışanlar olarak sınırlandırılmıştır. Basit tesadüfi örnekleme yolu ile seçilen katılımcılara anket uygulanması elektronik posta yoluyla Kasım 2020 tarihinde dağıtılmıştır. Ocak 2021 'e kadar elde edilen veriler üzerinden birtakım istatistiksel analizler gerçekleştirilmiştir. Araştırmaya 53 kişi katılğı bilinmektedir. Bunun \%79'unu erkek katılımcılar, \%21'ini kadın katılımcılar oluşturmaktadır.

\subsubsection{Anket Geliştirme}

Bu araştırmada, literatür çalışmalarına dayanılarak belirlenen iki bölümden oluşan ölçek verilerin toplanması amacıyla kullanılmıştır. Bunlar; katılımcılara ait demografik değişkenlerin olduğu birinci bölüm ve dünya klasmanındaki güvenlik algısını ölçmeye yönelik ilişkili olduğu saptanan boyutlardan oluşan ikinci bölümdür. Birinci bölüm katılımcıların demografik özelliklerine ilişkin 8 sorudan oluşmaktadır. İkinci bölümde ise; Güvenlik kültürü (Safety Culture Scale: SCS), Liderlik Ölçeği (Safety Leadership Scale: SLS), Güvenlik Planı/Programı (Safety Plan Scale) ve Güvenlik Performansı (Safety Performans Scale: SPS) boyutunu ölçmeye yönelik dört kısım 13 değişkenden oluşan bir ölçek belirlenmiştir. Anket toplam 77 sorudan oluşmaktadır. Bu araştırmada, Kadercilik ve Raporlama Kültürü ölçekleri (hiç katılmıyorum ve tamamen katılıyorum arası değişen) altılı likert ölçek kullanılarak cevaplanacak sorulardan oluşurken, diğer ölçekler (Kesinlikle Katılmıyorum; Kesinlikle Katılıyorum arası) beşli likert ölçek kullanılarak cevaplanacak sorulardan oluşmaktadır. Demografik değişkenler 8 soru Gürbüz'ün (2017), Güvenlik Kültürü Ölçeği 41 soru Dursun' un (2011), Liderlik Ölçeği 5 soru Boroughf' un (2012), Güvenlik Planı Ölçeği 17 soru HSE (1999), Güvenlik Performansı Ölçeği 6 soru Dursun'un (2011) çalışmalarından alıntılanmıştır.

\subsubsection{Araştırma Bulguları}

Araştırma kapsamında uygulanan anketten toplanan verilerin düzenlenmesinde MS Word, MS Excel (2007) kullanılmıştır. Verilerin IBM tarafindan geliştirilen "SPSS- 26.0" istatistik programı kullanılarak derlemeleri yapılmıştır. Modele ilişkin faktörlerin birbirleri ile olan ilişsilerini analiz etmek, birbiri ile ilişkilerininin karşılaştırılmasını yapmak için bir takım istatistiksel analizler kulllanılmıştır. Bunlar; verilerin frekanslarının dağılımları, Cronbach's Alpha güvenilirlik analizi, korelasyon, regresyon, ki-kare ve t-testidir (Sayıcı F., ve Öztürk T. 2020). Son bölümde, sonuçlar değerlendirilmiş ve birbirleri arasındaki ilişkiler incelenmiştir.

\subsubsection{Araştırmada Kullanılan Ölçeğin Güvenilirlik Analizi Sonucu ve Tanımlayıcı İstatistikler}

Anketi katılımcıya iletmeden önce, anketin güvenilirliğini belirlemek için Cronbach's Alpha güvenilirlik analizi yapılmıştır. Tablo 1 'de araştırmada kullanılan anketin güvenilirlik değerlerini göstermektedir. Analiz sonuçlarına göre ölçeğin güvenilirliğinin kabul edilebilir sınırlar içerisinde olduğu söylenebilir $(0,967>0,7)$. 
Tablo 4: Çalışılan İsyerinde İş Kazası Geçirme İstatistikleri

\begin{tabular}{ccc}
\hline \multicolumn{3}{c}{ Güveniliklik Analizi Sonuçları } \\
\hline Cronbach & Standartlaştırılmış Ö̆ğelere Dayalı & $\mathrm{N}$ \\
Alfa & Cronbach Alfa & \\
0,967 & 0,971 & 69 \\
\hline
\end{tabular}

Araştırmanın bırıncı bölümünde organızasyondaki çalışanlara Gürbüz'in (2017) yılındaki çalışmasından alıntılanan yaş, cinsiyet, medeni hali, eğitim seviyesi, pozisyonunuz, önceki çalışma yerlerinde veya mevcut işyerinde kazalara/ramak kala durumlarına uğrayıp uğramadığı gibi 8 demografik soru sorulmuştur. Tablo 2 demografik değişkenler bakımından katılımcıların istatistiksel dağılımları görülmektedir.

Araştırmaya katılanların \%79'unu erkek katılımcılar, \%21'ini kadın katılımcılar oluşturmaktadır. Sektörün büyük kısmını erkek çalışanlar oluşturması sebebiyle bu dağımındaki oranın gözlendiği söylenebilir.

\section{Tablo 2: İş Kazası Geçirme İstatistiklerinin Demografik Değişkenlere Göre Dă̆llımları}

\begin{tabular}{|c|c|c|}
\hline Demografik Değişkenler & Değerler & $\mathbf{N}$ \\
\hline \multirow[t]{3}{*}{ Cinsiyeti } & Kadın & 11 \\
\hline & Erkek & 42 \\
\hline & Toplam & 53 \\
\hline \multirow[t]{2}{*}{ Medeni Hali } & Evli & 38 \\
\hline & Bekar & 15 \\
\hline \multirow[t]{4}{*}{ Yaş Aralığı } & $18-29$ & 8 \\
\hline & $30-39$ & 23 \\
\hline & $40-49$ & 18 \\
\hline & $50-59$ & 4 \\
\hline \multirow[t]{6}{*}{ Eğitim Derecesi } & Doktora & 2 \\
\hline & Yüksek & 15 \\
\hline & Lisans & \\
\hline & Lisans & 20 \\
\hline & Ön Lisans & 7 \\
\hline & Lise & 9 \\
\hline \multirow[t]{5}{*}{ İşletmedeki Pozisyonu } & Müdür & 12 \\
\hline & Mühendis & 9 \\
\hline & Tekniker & 2 \\
\hline & Formen & 7 \\
\hline & Diğer & 23 \\
\hline
\end{tabular}

Tablo 3 ve Tablo 4'te sırasıyla katılımcıların iş yaşantısı süresince iş kazası geçirme istatistikleri ve çalışılan işyerinde iş kazası geçirme istatistikleri görülmektedir.

Katılımcıların \%94' ü iş hayatı süresince iş kazasına uğramadıklarını belirtirken, $\% 6$ 's $\mathrm{s}$ iş hayatı süresince en az birkez iş kazasına uğradığını belirtmiştir.

Katılımcıların \%98' i mevcut işyerinde iş kazasına uğramadıklarını belirtirken, \%2 'si mevcut işyerinde en az birkez iş kazası geçirdiğini ifade etmiştir.

Tablo 3: Işs Yaşantısı Süresince İ̧̧ Kazası Geçirme İstatistikleri

\begin{tabular}{lcc}
\hline & Sıklık & Yüzde \\
\hline Kaza geçiren & 3 & 6 \\
Kaza geçirmeyen & 50 & 94 \\
\hline
\end{tabular}

\begin{tabular}{lcc}
\hline & Sıklık & Yüzde \\
\hline Kaza geçiren & 1 & 2 \\
Kaza geçirmeyen & 52 & 98 \\
\hline
\end{tabular}

Tablo 4' e göre katılımcıların \%2'si daha önce iş kazasına uğradıklarını ifade ederken, \%98'i iş kazasına uğramadıklarını belirtmiştir. Mevcut veriler 1şı̆̆ında katılımcıların iş kazasına uğrama oranlarının oldukça düşük olduğu ve bu durumun elektronik sektöründe iş kazası yaşanma riskinin diğer sektörlere nispeten daha düşük olmasından kaynaklandığı söylenebilir.

Demografik değişkenlerden olan cinsiyet değişkenine göre iş kazasına uğrama durumunda değişiklik olup/ olmadığına bakmak için ki- kare testi uygulanmıştır. Tablo 5 'te ki- kare testinin analiz sonuçları görülmektedir.

Tablo 5: Katılımcıların Çalıştıkları İşyerinde Cinsiyetlerine Göre İ̧̧ Kazası Geçirme Istatistikleri

\begin{tabular}{l|l|l|l|l}
\hline Erkek & Toplam & 2 & 40 & 42 \\
\hline & \% Cinsiyet & $4,8 \%$ & $95,2 \%$ & $100,0 \%$ \\
\hline & \%İş Kazası & $66,7 \%$ & $80,0 \%$ & $79,2 \%$ \\
\hline Kadın & Toplam & 1 & 10 & 11 \\
\hline & \% Cinsiyet & $9,1 \%$ & $90,9 \%$ & $100,0 \%$ \\
\hline & \%İş Kazası & $33,3 \%$ & $20,0 \%$ & $20,8 \%$ \\
\hline Toplam & Toplam & 3 & 50 & 53 \\
\hline & \% Cinsiyet & $5,7 \%$ & $94,3 \%$ & $100,0 \%$ \\
\hline & \%İş Kazası & $100,0 \%$ & $100,0 \%$ & $100,0 \%$ \\
\hline
\end{tabular}

Pearson Ki-Kare Testi: 0,306; df: 1

Tablo 5'te pearson ki-kare testi analizi ile iş yaşantısı süresince iş kazasına uğrama ile cinsiyet karşılaştırması yapıldı̆̆ında, erkek veya kadınlar arasında istatistiğe dayalı anlamlı bir ilişki vardır. Bu ilişkinin yaklaşık \%31 düzeyinde anlamlı olduğunu söylenmektedir. Tablo 5 'tede belirtildiği gibi, iş kazası geçirenlerin \%4,8'inin erkek, \%9,1'inin de kadın olduğunu söylenmektedir. Aynı zamanda tablo bize, erkeklerin \%66,7'si kadınlarında \%33,3' ü iş kazası geçirdiğini göstermektedir.

\subsubsection{Demografik Değișkenler ve Güvenlik Kültürrü Değişkenleri Karşılaştırması}

Çalışmada kullanılan demografik değişkenler ile herbir güvenlik kültürü değişkeni arasında istatistiksel olarak nasıl bir ilişki söz konusu olduğu bu bölüm altında incelenmeye çalışılmıştır.

Demografik değişkenlerden cinsiyet değişkeni ile güvenlik kültürü değişkenlerinden cinsiyet değişkeni arasında farklılık olup olmadığı Tablo 6' da görülür. Tablo 6 'ya göre, cinsiyet değişkeni ele alındığında kadın çalışanların her bir güvenlik kültürü değişkenleri ortalamalarının daha yüksek olduğu söylenmektedir (kadercilik boyutu hariç). Cinsiyet değişkeni ele alındığında her bir güvenlik kültürü değişkenleri bakımından istatistiksel olarak $\% 5$ anlamlılık düzeyinde fark olmadığ söylenebilir ( $\mathrm{p}>0,05)$.

Demografik değişkenlerden medeni durum değişkeni ile her bir güvenlik kültürü değişkeni arasında farklılık olup olmadığı Tablo 7' de gözükmektedir. Tablo 7 'ye göre, medeni durum değişkeni ele alındığında evli çalışanların her bir güvenlik kültürü 
değişkenleri ortalamalarının daha yüksek olduğunu söylenebilir (kadercilik boyutu hariç). Medeni durum değişkeni ele alındığında herbir güvenlik kültürü değişkeni aralarındaki bu farkın istatistiksel olarak $\% 5$ anlamlılık düzeyinde anlamlı olduduğu söylenebilir $(\mathrm{p}>0,05)$.

Tablo 6: Güvenlik Kültürü Değişkenlerinin Cinsiyete Göre Karşılaştırması

\begin{tabular}{|c|c|c|c|c|c|c|c|c|}
\hline & \multicolumn{8}{|c|}{ Demografik Değişkenlerden Cinsiyet Değişkeni } \\
\hline & \multicolumn{3}{|c|}{ Erkek } & \multicolumn{3}{|c|}{ Kadın } & \multicolumn{2}{|c|}{ Testler } \\
\hline & $\mathrm{N}$ & Ortalama & S.S. & $\mathrm{N}$ & Ortalama & S.S. & $\mathrm{t}$ & $(\mathrm{P})$ \\
\hline Yönetimin Bağlılı̆̆ & 42 & 4,1696 & 0,91057 & 11 & 4,1705 & 0,43400 & $-0,003$ & 0,998 \\
\hline Güvenlik Önceliği & 42 & 4,0119 & 0,81703 & 11 & 3,8864 & 0,30339 & 0,498 & $\overline{0,621}$ \\
\hline Güvenlik İletişimi & 42 & 4,0619 & 0,99018 & 11 & 4,2727 & 0,58837 & $-0,673$ & $\overline{0,504}$ \\
\hline Güvenlik Eğitimi & 42 & 4,3274 & 0,80677 & 11 & 4,7045 & 0,45851 & $-1,482$ & 0,144 \\
\hline Güvenlik Farkındalığı ve Yetkinlik & 42 & 4,5714 & 0,52744 & 11 & 4,7455 & 0,50668 & $-0,982$ & 0,331 \\
\hline Çalışanların Katılımı & 42 & 3,8036 & 0,91654 & 11 & 3,8636 & 0,87581 & $-0,195$ & $\overline{0,846}$ \\
\hline Kadercilik & 42 & 2,5374 & 1,05111 & 11 & 2,3117 & 0,55629 & 0,684 & 0,497 \\
\hline Raporlama Kültürü & 42 & 4,2083 & 0,85703 & 11 & 4,4545 & 0,26968 & $-0,935$ & 0,354 \\
\hline
\end{tabular}

Demografik değişkenlerden eğitim derecesi boyutunun her bir güvenlik kültürü değişkeni arasında farklılık olup olmadığ 1 Tablo 8' de gözükmektedir. Tablo 8 'e göre, eğitim derecesi değişkeni ile güvenlik kültürü değişkenleri aralarında \%5 anlamlılık düzeyinde farklılık olmadığı söylenebilir ( $\mathrm{p}>0,05)$.

Demografik değişkenlerden katılımcıların yaş grupları ile her bir güvenlik kültürü değişkeni arasında yakınlık Tablo 9 içerisinde gözükmektedir. Bu tablodaki veriler doğrultusunda, yaş grupları değişkeni ele alındığında güvenlik kültürü değişkenleri bakımından istatistiksel olarak $\% 5$ anlamlılık düzeyinde farkın olduduğu söylenebilir $(p>0,05)$. Raporlama kültürü ve yaş değişkenleri karşılaştırıldığında istatistiksel olarak anlamlı bir farkın olduğu söylenebilir $(\mathrm{p}<0,05)$. Araştırma verileri ankete katılan 30-39 yaşları arasındaki çalışanların raporlama kültürü algılarının daha yüksek olduğunu göstemiştir. 50 yaş üstü katılımcılar araştırmaya dahil edilmemiştir.

Tablo 7: Güvenlik Kültürü Değişkenlerinin Medeni Durumlara Göre Karşılaştırması

\begin{tabular}{|l|c|c|c|c|c|c|c|c|}
\cline { 2 - 9 } \multicolumn{1}{c|}{} & \multicolumn{9}{c|}{ Evli } & \multicolumn{4}{c|}{ Medeni Durum } \\
\cline { 2 - 9 } \multicolumn{1}{c|}{} & \multicolumn{3}{c|}{ Bekar } & \multicolumn{2}{c|}{ Testler } \\
\cline { 2 - 9 } \multicolumn{1}{c|}{} & $\mathrm{N}$ & Ortalama & S.S. & $\mathrm{N}$ & Ortalama & S.S. & t & $(\mathrm{P})$ \\
\hline Yönetimin Bağl1lığı & 38 & 4,2730 & 0,82243 & 15 & 3,9083 & 0,82031 & 1,455 & 0,152 \\
\hline Güvenlik Önceliği & 38 & 4,0461 & 0,77297 & 15 & 3,8333 & 0,64550 & 0,942 & 0,350 \\
\hline Güvenlik İletişimi & 38 & 4,1579 & 0,95426 & 15 & 3,9733 & 0,84470 & 0,654 & 0,516 \\
\hline Güvenlik Eğitimi & 38 & 4,4605 & 0,66151 & 15 & 4,2667 & 0,97955 & 0,834 & 0,408 \\
\hline Güvenlik Farkındalığı ve Yetkinlik & 38 & 4,6632 & 0,50747 & 15 & 4,4667 & 0,55377 & 1,238 & 0,221 \\
\hline Çalışanların Katılımı & 38 & 3,8947 & 0,92931 & 15 & 3,6167 & 0,81759 & 1,013 & 0,316 \\
\hline Kadercilik & 38 & 2,4398 & 1,00049 & 15 & 2,6190 & 0,90458 & $-0,603$ & 0,549 \\
\hline Raporlama Kültürü & 38 & 4,3224 & 0,74641 & 15 & 4,1000 & 0,85461 & 0,938 & 0,353 \\
\hline
\end{tabular}

Demografik değişkenlerden işletmedeki pozisyonu değişkeni ile her bir güvenlik kültürü değişkeni arasında farklılık olup olmadığg Tablo 10' da gözükmektedir. Tablo 10'a göre, yöneticilik konumunda çalışanların, kadercilik, çalışanların katılımı ve güvenlik önceliği değişkenleri hariç diğer tüm değişkenler bakımından daha yüksek ortalamalara sahip olduğu söylenebilir. Başka bir ifadeyle, yönetimin bağlılığı, iletişimi, eğitimi, raporlama kültürü ve güvenlik yetkinliği ve farkındalığı değişkenleri bakımından yöneticilerin başka seviyede çalışan kişilere oranla daha yüksek alg1 düzeyine sahip olduğu söylenebilir. Buna göre, ifade edilen değişkenler bakımından istatistiksel olarak \%5 anlamlılık düzeyinde farkın olduğu söylenebilir $(p>0,05)$. Diğer taraftan, kadercilik, çalışanların katılımı ve güvenlik önceliği değişkenleri açısından baktığımızda ise, çalışanların kadercilik algılarının, yönetici olarak çalışanların kadercilik algılarından daha büyük ortalamalara sahip olduğunu ve aralarında istatistiksel olarak \%5 anlamlılık düzeyinde bir ilişki olmadığı söylenebilir $(\mathrm{p}<0,05)$. Bir diğer ifade ile, çalışanların yönetici konumunda bulunanlara göre iş güvenliği anlamında daha kaderci bir düşünce anlayışına sahip olduğu söylenebilir. 
Tablo 8: Eğitim Seviyeleri ve Güvenlik Kültürü Ölçeklerinin Karşılaştırması

\begin{tabular}{|c|c|c|c|c|c|c|c|c|c|c|c|c|c|c|c|}
\hline & \multicolumn{15}{|c|}{ Ĕgitim Sevileri } \\
\hline & \multicolumn{3}{|c|}{ Lise } & \multicolumn{3}{|c|}{ Önlisans } & \multicolumn{3}{|c|}{ Lisans } & \multicolumn{3}{|c|}{ Y. Lisans } & \multicolumn{3}{|c|}{ Doktora } \\
\hline & $\mathrm{N}$ & Ort. & S.S. & $\mathrm{N}$ & Ort. & S.S. & $\mathrm{N}$ & Ort. & S.S. & $\mathrm{N}$ & Ort. & S.S. & $\mathrm{N}$ & Ort. & S.S. \\
\hline $\begin{array}{l}\text { Yönetimin } \\
\text { Bağl1lığ }\end{array}$ & 9 & 4,5139 & 0,61379 & 7 & 3,7679 & 1,47625 & 20 & 4,3438 & 0,71621 & 15 & 3,9500 & 0,67612 & 2 & 3,9375 & 0,08839 \\
\hline $\begin{array}{l}\text { Güvenlik } \\
\text { Önceliği }\end{array}$ & 9 & 4,4167 & 0,80039 & 7 & 3,7500 & 1,27475 & 20 & 4,0250 & 0,70197 & 15 & 3,8833 & 0,24761 & 2 & 3,2500 & 0,00000 \\
\hline $\begin{array}{l}\text { Güvenlik } \\
\text { İletişimi }\end{array}$ & 9 & 4,2444 & 0,94222 & 7 & 3,6571 & 1,57359 & 20 & 4,3300 & 0,81635 & 15 & 3,9467 & 0,67387 & 2 & 4,0000 & 0,28284 \\
\hline Güvenlik Eğitimi & 9 & 4,4167 & 0,79057 & 7 & 4,5714 & 0,42608 & 20 & 4,5375 & 0,83617 & 15 & 4,2000 & 0,80844 & 2 & 4,0000 & 0,00000 \\
\hline $\begin{array}{l}\text { Güvenlik } \\
\text { Farkındalığı ve } \\
\text { Yetkinlik }\end{array}$ & 9 & 4,4667 & 0,61644 & 7 & 4,8286 & 0,37289 & 20 & 4,7400 & 0,38987 & 15 & 4,4000 & 0,64143 & 2 & 4,7000 & 0,42426 \\
\hline $\begin{array}{l}\text { Çalışanların } \\
\text { Katılımı }\end{array}$ & 9 & 4,1667 & 1,00000 & 7 & 3,8929 & 1,05926 & 20 & 3,9375 & 0,90639 & 15 & 3,5167 & 0,71631 & 2 & 3,0000 & 0,70711 \\
\hline Kadercilik & 9 & 3,1111 & 1,14459 & 7 & 2,7143 & 1,33248 & 20 & 2,3929 & 0,85322 & 15 & 2,1905 & 0,73771 & 2 & 2,1429 & 0,80812 \\
\hline $\begin{array}{l}\text { Raporlama } \\
\text { Kültürü }\end{array}$ & 9 & 3,9444 & 1,24234 & 7 & 4,2143 & 1,04511 & 20 & 4,4375 & 0,56705 & 15 & 4,2500 & 0,53452 & 2 & 4,1250 & 0,88388 \\
\hline
\end{tabular}

Tablo 9: Güvenlik Kültürü Değişkenlerinin Katılımcıların Yaşlarına Göre Karşılaştırması

\begin{tabular}{|c|c|c|c|c|c|c|c|c|c|c|c|}
\hline & \multicolumn{11}{|c|}{ Yaş Grupları } \\
\hline & \multicolumn{3}{|c|}{ 18-29 } & \multicolumn{3}{|c|}{$30-39$} & \multicolumn{3}{|c|}{$40-49$} & \multirow[b]{2}{*}{$\mathrm{F}$} & \multirow[b]{2}{*}{$\mathrm{P}$} \\
\hline & $\mathrm{N}$ & Ort. & S.S. & $\mathrm{N}$ & Ort. & S.S. & $\mathrm{N}$ & Ort. & S.S. & & \\
\hline Yönetimin Bağlılı̆̆ 1 & 8 & 3,7500 & 0,95665 & 41 & 4,2561 & 0,81679 & 4 & 4,1250 & 0,59512 & $\begin{array}{c}1,26 \\
1 \\
\end{array}$ & $\begin{array}{c}0,29 \\
2 \\
\end{array}$ \\
\hline Güvenlik Önceliği & 8 & 3,9688 & 0,31161 & 41 & 3,9512 & 0,81436 & 4 & 4,3750 & 0,43301 & $\begin{array}{c}0,59 \\
2\end{array}$ & $\begin{array}{c}0,55 \\
7 \\
\end{array}$ \\
\hline Güvenlik İletişimi & 8 & 3,8500 & 0,76904 & 41 & 4,1610 & 0,96252 & 4 & 4,0500 & 0,85440 & $\begin{array}{c}0,38 \\
1\end{array}$ & $\begin{array}{c}0,68 \\
5 \\
\end{array}$ \\
\hline Güvenlik Eğitimi & 8 & 4,0625 & 0,92341 & 41 & 4,4817 & 0,71017 & 4 & 4,3125 & 0,94373 & $\begin{array}{c}1,05 \\
3 \\
\end{array}$ & $\begin{array}{c}0,35 \\
6 \\
\end{array}$ \\
\hline Güvenlik Farkındalığı ve Yetkinlik & 8 & 4,2750 & 0,82765 & 41 & 4,6829 & 0,42656 & 4 & 4,5000 & 0,57735 & $\begin{array}{c}2,22 \\
6\end{array}$ & $\begin{array}{c}0,11 \\
9\end{array}$ \\
\hline Çalışanların Katılımı & 8 & 3,4688 & 1,02153 & 41 & 3,8780 & 0,87343 & 4 & 3,8750 & 1,03078 & $\begin{array}{c}0,69 \\
3\end{array}$ & $\begin{array}{c}0,50 \\
5 \\
\end{array}$ \\
\hline Kadercilik & 8 & 2,1964 & 0,72417 & 41 & 2,5645 & 0,92248 & 4 & 2,3214 & 1,83457 & $\begin{array}{c}0,53 \\
9\end{array}$ & $\begin{array}{c}0,58 \\
7\end{array}$ \\
\hline Raporlama Kültürü & 8 & 3,9688 & 0,91063 & 41 & 4,3963 & 0,59942 & 4 & 3,4375 & 1,53263 & $\begin{array}{c}3,80 \\
8\end{array}$ & $\begin{array}{c}0,02 \\
9\end{array}$ \\
\hline
\end{tabular}

Tablo 10. Güvenlik Kültürü Değişsenlerinin Katılımcıların İş Yerindeki Pozisyonlarına Göre Karşılaştırması

\begin{tabular}{|c|c|c|c|c|c|c|c|c|}
\hline & \multicolumn{8}{|c|}{ Çalıșanların İșteki Konumu } \\
\hline & \multicolumn{3}{|c|}{ Yönetici } & \multicolumn{3}{|c|}{ Çalışan } & \multicolumn{2}{|c|}{ Testler } \\
\hline & $\mathrm{N}$ & Ortalama & S.S. & $\mathrm{N}$ & Ortalama & S.S. & $\mathrm{t}$ & $\mathrm{P}$ \\
\hline Yönetimin Bağlılı̆g & 12 & 4,3229 & 0,48400 & 41 & 4,1250 & 0,90743 & 0,723 & 0,473 \\
\hline Güvenlik Önceliği & 12 & 3,9792 & 0,55859 & 41 & 3,9878 & 0,79047 & $-0,035$ & 0,972 \\
\hline Güvenlik İletişimi & 12 & 4,2500 & 0,57287 & 41 & 4,0634 & 1,00144 & 0,614 & 0,542 \\
\hline Güvenlik Eğitimi & 12 & 4,4792 & 0,57858 & 41 & 4,3841 & 0,81028 & 0,378 & 0,707 \\
\hline Güvenlik Farkındalığı ve Yetkinlik & 12 & 4,7500 & 0,30896 & 41 & 4,5659 & 0,56728 & 1,074 & 0,288 \\
\hline Çalışanların Katılımı & 12 & 3,8125 & 0,76963 & 41 & 3,8171 & 0,94377 & $-0,015$ & 0,988 \\
\hline Kadercilik & 12 & 2,2857 & 1,06557 & 41 & 2,5505 & 0,94467 & $-0,830$ & 0,410 \\
\hline Raporlama Kültürü & 12 & 4,3333 & 0,66856 & 41 & 4,2378 & 0,81193 & 0,372 & 0,712 \\
\hline
\end{tabular}

\subsubsection{Güvenlik Kültürü ve Güvenlik Performanst Ölçeklerinin Karşılaştırması}

Güvenlik performansı değişkenlerinden çalışma hayatında iş kazasına uğrama değişkeni ile her bir güvenlik kültürü değişkeni arasında farklılık olup olmadığı Tablo 11' de gözükmektedir.

e-ISSN: 2148-2683
Çalışma hayatında iş kazasına uğrayan çalışanların çalışanların katılımı, raporlama kültürü, güvenlik katılımı ve eğitimi ortalamaları iş kazasına uğramayanlardan daha düşük bulunmakla beraber, ifade edilen değişkenler arasında istatistiksel olarak \%5 anlamlılık düzeyinde farklılık bulunmadığ söylenebilir ( $\mathrm{p}>0,05)$. 
Bununla birlikte, işyerinde iş kazası geçirme durumları ve her bir güvenlik kültürü değişkeni arasında farklılık olup olmadığı Tablo 12' de görülmektedir. Elde edilen sonuçlara göre; iş kazasına uğramayan çalışanların her bir güvenlik kültürü değişkenlerinin ortalamaları daha yüksek ortalamalara sahip olduğunu ve aralarındaki bu farklılığın istatistiksel olarak da anlamlı olmadığı söylenebilir ( $\mathrm{p}>0,05)$.
Güvenlik performansı değişkenlerinden biri olan güvenli davranış değişkeni ile her bir güvenlik kültürü değişkeni arasında farklılık olup olmadığı Tablo 13' de görülmektedir. Bu iki ölçek arasında korelasyon analizi istatistiksel analizi uygulanmıştır.

Tablo 11. Güvenlik Kültürü̈ Değişkenlerinin Katılımcıların İş Yaşantısı Süresince İş Kazası Geçirmelerine göre Istatistikleri

\begin{tabular}{|c|c|c|c|c|c|c|c|c|}
\hline & \multicolumn{8}{|c|}{ Çalışma Hayatında İş Kazası } \\
\hline & \multicolumn{3}{|c|}{ Evet } & \multicolumn{3}{|c|}{ Hayır } & \multicolumn{2}{|c|}{ Testler } \\
\hline & $\mathrm{N}$ & Ortalama & S.S. & $\mathrm{N}$ & Ortalama & S.S. & $\mathrm{t}$ & $\mathrm{P}$ \\
\hline Yönetimin Bağlılığ1 & 3 & 4,3750 & 0,62500 & 50 & 4,1575 & 0,84471 & 0,437 & 0,664 \\
\hline Güvenlik Önceliği & 3 & 4,1667 & 0,76376 & 50 & 3,9750 & 0,74445 & 0,433 & 0,667 \\
\hline Güvenlik İletişimi & 3 & 4,0667 & 0,83267 & 50 & 4,1080 & 0,93303 & $-0,075$ & 0,941 \\
\hline Güvenlik Eğitimi & 3 & 4,3333 & 0,62915 & 50 & 4,4100 & 0,77222 & $-0,168$ & 0,867 \\
\hline Güvenlik Farkındalığı ve Yetkinlik & 3 & 4,6667 & 0,57735 & 50 & 4,6040 & 0,52604 & 0,200 & 0,843 \\
\hline Çalışanların Katılımı & 3 & 3,5833 & 1,23322 & 50 & 3,8300 & 0,89134 & $-0,457$ & 0,649 \\
\hline Kadercilik & 3 & 2,5238 & 1,08170 & 50 & 2,4886 & 0,97409 & 0,061 & 0,952 \\
\hline Raporlama Kültürü & 3 & 4,1667 & 1,04083 & 50 & 4,2650 & 0,77164 & $-0,211$ & 0,834 \\
\hline
\end{tabular}

Tablo 12. Güvenlik Kültürü Değişkenlerinin Katılımcıların Çalıştığı Işs Yerinde Işs Kazası Geçirmelerine Göre İstatistikleri

\begin{tabular}{|l|c|c|c|c|c|c|c|c|}
\cline { 2 - 8 } \multicolumn{1}{c|}{} & \multicolumn{9}{c|}{ İsyerinde İş Kazası } \\
\cline { 2 - 9 } \multicolumn{1}{c|}{} & \multicolumn{4}{c|}{ Evet } & \multicolumn{3}{c|}{ Hayır } & \multicolumn{2}{c|}{ Testler } \\
\cline { 2 - 8 } \multicolumn{1}{c|}{} & $\mathrm{N}$ & Ort. & S.S. & $\mathrm{N}$ & Ort. & S.S. & t & P \\
\hline Yönetimin Bağlılı̆ı & 1 & 5,0000 & & 52 & 4,1538 & 0,83049 & 1,009 & 0,318 \\
\hline Güvenlik Önceliği & 1 & 5,0000 & & 52 & 3,9663 & 0,73269 & 1,397 & 0,168 \\
\hline Güvenlik İletişimi & 1 & 5,0000 & & 52 & 4,0885 & 0,92071 & 0,981 & 0,331 \\
\hline Güvenlik Eğitimi & 1 & 5,0000 & & 52 & 4,3942 & 0,76271 & 0,787 & 0,435 \\
\hline Güvenlik Farkındalığı ve Yetkinlik & 1 & 5,0000 & & 52 & 4,6000 & 0,52543 & 0,754 & 0,454 \\
\hline Çalışanların Katılımı & 1 & 5,0000 & & 52 & 3,7933 & 0,89350 & 1,338 & 0,187 \\
\hline Kadercilik & 1 & 3,0000 & & 52 & 2,4808 & 0,97591 & 0,527 & 0,600 \\
\hline Raporlama Kültürüu & 1 & 5,0000 & & 52 & 4,2452 & 0,77727 & 0,962 & 0,341 \\
\hline
\end{tabular}

Tablo 13. Korelasyon Analizi Sonuçlarna göre Güvenlik Kültürü Değişkenleri ve Güvenli Davranış Değişkeni Karşılaştırması

\begin{tabular}{l|c|c|c|c|c|c|c|c|c}
\hline & $\mathbf{1}$ & $\mathbf{2}$ & $\mathbf{3}$ & $\mathbf{4}$ & $\mathbf{5}$ & $\mathbf{6}$ & $\mathbf{7}$ & $\mathbf{8}$ & $\mathbf{9}$ \\
\hline Yönetimin Bağlılı̆̆ & 1 & & & & & & & & \\
\hline Güvenlik Önceliği &, $669^{* *}$ & 1 & & & & & & \\
\hline Güvenlik İletişimi &, $813^{* *}$ &, $690^{* *}$ & 1 & & & & & \\
\hline Güvenlik Eğitimi &, $645^{* *}$ &, $475^{* *}$ &, $698^{* *}$ & 1 & & & & & \\
\hline Güvenlik Farkındalığı ve Yetkinlik &, $433^{* *}$ & 0,236 &, $462^{* *}$ &, $604^{* *}$ & 1 & & & & \\
\hline Çalışanların Katılımı &, $668^{* *}$ &, $534^{* *}$ &, $768^{* *}$ &, $605^{* *}$ &, $458^{* *}$ & 1 & & & \\
\hline Kadercilik &, $311^{*}$ & 0,174 & 0,148 & 0,141 & 0,028 &, $337^{*}$ & 1 & \\
\hline Raporlama Kültürü &, $550^{* *}$ &, $302^{*}$ &, $523^{* *}$ &, $598^{* *}$ &, $537^{* *}$ &, $437^{* *}$ & 0,225 & 1 & \\
\hline Güvenli Davranış &, $319^{*}$ & 0,124 &, $348^{*}$ &, $573^{* *}$ &, $684^{* *}$ &, $448^{* *}$ & 0,241 &, $622^{* *}$ & 1 \\
\hline
\end{tabular}

$* * \mathrm{p}<0,01 \quad * \mathrm{p}<0,05$

Güvenlik kültürü değişkenlerinin birbirleri ile olan korelasyon analizi sonuçlarına baktığımızda, kadercilik değişkeni $(\mathrm{r}=, 311 ; \mathrm{p}<0,05)$ ile zayıf ve pozitif yönlü ilişki görülürken; güvenlik iletişimi değişkeni $(\mathrm{r}=, 813 ; \mathrm{p}<0,01)$ ile istatistiksel olarak güçlü ve pozitif yönde anlamlı olduğu söylenebilir.

Yönetimin bağlılığı değişkeni, kadercilik ve güvenlik farkındalığı ve yetkinliği değişkenleri arasındaki bu farklılığın istatistiksel olarak da anlamlı bulunmadığı söylenebilir $(\mathrm{p}>0,05)$.
Güvenlik önceliği değişkeni, raporlama kültürü değişkeni $(\mathrm{r}=, 302 ; \mathrm{p}<0,05)$ ile zayıf ve pozitif yönlü ilişki görülürken; güvenlik iletişimi değişkeni $(r=, 690 ; p<0,01)$ ile güçlü ve pozitif yönde istatistiksel olarak da anlamlı bulunduğu söylenebilir. Aynı zamanda, güvenlik farkındalığı ve yetkinliği boyutları ile kadercilik boyutları dışındaki boyutlarla güçlü ve pozitif yönde istatistiksel olarak da anlamlı bulunduğu söylenebilir. 
Güvenlik iletişimi değişkeni açısından baktığımızda, güvenlik farkındalığı veya yetkinlik değişkeni $(r=, 462 ; \mathrm{p}<0,01)$ ile olumlu yönde zayıf yakınlık görülürken; güvenlik iletişimi değişkeni $(r=, 813 ; p<0,01)$ ile olumlu yönde güçlü yakınlık görülmektedir. Güvenlik iletişimi ve kadercilik değişkenlerinin arasında istatistiksel olarak $\% 5$ anlamlılık düzeyinde farklılık bulunmadığı söylenebilir ( $\mathrm{p}>0,05)$.

Güvenlik eğitimi değişkeni, kadercilik dışındaki diğer bütün boyutlarla aralarındaki ilişkinin pozitif yönlü istatistiksel olarak da anlamlı bulunduğu söylenebilir. Güvenlik eğitimi değişkeni, güvenlik önceliği boyutu $(\mathrm{r}=, 475 ; \mathrm{p}<0,01)$ ile zayıf yakınlık gösterirken; güvenlik iletişimi boyutu $(\mathrm{r}=, 698 ; \mathrm{p}<0,01)$ ile güçlü yakınlık görüldügü söylenebilir. Kadercilik ve güvenlik iletişimi boyutları aralarında istatistiksel olarak $\% 5$ anlamlılık düzeyinde farklılık bulunmadığ 1 söylenebilir ( $\mathrm{p}>0,05)$.

Güvenlik farkındalığı ve yetkinlik değişkeninin ise, kadercilik dışındaki diğer herbir değişken ile aralarındaki ilişkinin pozitif yönlü istatistiksel olarak da anlamlı bulunduğu söylenebilir. Güvenlik farkındalığı ve yetkinlik, yönetimin bağlılı̆̆ değişkeni ( $\mathrm{r}=, 433 ; \mathrm{p}<0,01)$ ile zayıf yakınlık gösterirken, güvenlik eğitimi değişkeni $(r=, 604 ; \mathrm{p}<0,01)$ ile güçlü yakınlık göstermektedir. Ayrıca, kadercilik ve güvenlik eğitimi boyutları arasında ise anlamlı bir ilişki bulunmadığı söylenebilir ( $\mathrm{p}>0,05)$.

Çalışanların katılımı değişkeni ile diğer bütün boyutlar aralarındaki farkın pozitif yönlü istatistiksel olarak da anlamlı bulunduğu söylenebilir. Çalışanların katılımı değişkeni, kadercilik boyutu $(\mathrm{r}=, 337 ; \mathrm{p}<0,05)$ ile zayıf yakınlık gösterirken, güvenlik iletişimi değişkeni $(r=, 768 ; p<0,01$ ile güçlü yakınlık göstermektedir.

Kadercilik değişkenin, yönetimin bağlılığı ve çalışanların katılımı hariç diğer tüm değişkenlerle ilişkilerinin pozitif yönlü istatistiksel olarak da anlamlı bulunmadığı söylenebilir ( $\mathrm{p}>0,05)$. Ayrıca, kadercilik boyutu ile yönetimin bağlılığı ve çalışanların katılımı arasında zayıf pozitif yönlü anlamlı bir ilişki vardır.
Son olarak raporlama kültürü değişkeni açısından baktığımızda, kadercilik haricindeki büyün boyutlarla ilişkilerinin pozitif yönlü istatistiksel olarak da anlamlı bulunduğu söylenebilir. Ancak bu ilişki, diğer değişkenlerin kendi aralarındaki ilişkilere göre daha zayıftır. Raporlama kültürü, güvenlik önceliği değişkeni $(r=, 302 ; \mathrm{p}<0,05)$ ile zayıf yakınlık gösterirken, güvenlik eğitimi değişkeni $r=, 598$; $p<0,01$ ) ile güçlü yakınlık göstermektedir. Ayrıca, kadercilik ve raporlama kültürü boyutları aralarında istatistiksel olarak $\% 5$ anlamlılık düzeyinde farklılık bulunmadığı söylenebilir ( $\mathrm{p}>0,05)$.

Güvenlik performansı değişkenlerinden güvenli davranış boyutunun herbir güvenlik kültürü değişkeni ile korelasyon analizi sonuçlarına baktığımızda ise, kadercilik ve güvenlik önceliğgi dışındaki diğer bütün boyutlarla aralarındaki ilişkinin pozitif yönlü istatistiksel olarak da anlamlı bulunduğu söylenebilir. Güvenli davranış değişkeni, güvenlik farkındalığı ve yetkinlik $(r=, 684 ; p<0,01)$ ile olumlu yakınlık göstermektedir. Buna göre, çalışanların güvenliğe yönelik farkındalığı ve yetkinlikleri arttıkça, daha fazla güvenli davranış sergilemekte oldukları söylenebilir. Aynı şekilde, çalışanların iş sağlığı ve güvenliği uygulamalarına katılması, raporlamadaki artış, güvenlik iletişimi ve yönetimin bağlılığı boyutlarındaki ilerlemeler güvenli davranış gösterme eğilimlerini arttırmaktadır. Güvenli davranış değişkeni ile kadercilik ve güvenlik önceliği değişkenleri aralarında istatistiksel olarak \%5 anlamlılık düzeyinde farklılık bulunmadığı söylenebilir ( $\mathrm{p}>0,05)$.

Herbir güvenlik kültürü değişkeninin güvenlik performansı değişkenlerinden güvenli davranış değişkeni ilişkisini incelemek ve birbirleri üzerindeki etkiyi anlamak amacıyla regresyon analizi gerçekleştirilmiştir. Regresyon analizinden elde edilen veriler Tablo 14' de gözükmektedir. Gerçekleştirilen F Testi sonucuna göre; modelin $0,01 \quad(\mathrm{~F}=10,16)$ seviyesinde mantıklı olduğu söylenebilir. Güvenli davranıştaki (bağımlı değişken) değişmenin \%58'ünün kullanılan bağımsız değişkenler tarafından açıklandı̆̆ görülmektedir (Düzeltilmiş $\mathrm{R}^{2}=, 585$ ).

Tablo 14. Regresyon Analizi Sonuçlarına göre Güvenlik Kültürü Değişkenleri ve Güvenli Davranış Değişkeni Karşılaştırılması

\begin{tabular}{|c|c|c|}
\hline \multirow[t]{2}{*}{ Bağımsız Değişken: Güvenlik Kültürü } & \multicolumn{2}{|c|}{ Bağımlı Değişken: Güvenli Davranış } \\
\hline & Beta & $\mathrm{t}$ \\
\hline Yönetimin Bağlılı̆̆ & 1,009 & 0,318 \\
\hline Güvenlik Önceliği & 1,397 & 0,168 \\
\hline Güvenlik İletişimi & 0,981 & 0,331 \\
\hline Güvenlik Eğitimi & 0,787 & 0,435 \\
\hline Güvenlik Farkındalığı ve Yetkinlik & 0,754 & 0,454 \\
\hline Çalışanların Katılımı & 1,338 & 0,187 \\
\hline Kadercilik & 0,527 & 0,600 \\
\hline Raporlama Kültürü & 0,962 & 0,341 \\
\hline
\end{tabular}

$\mathrm{R}^{2}: 0,649$, Düzeltilmiş $\mathrm{R}^{2}: 0,585, \mathrm{~F}: 10,16,{ }^{*} \mathrm{p}<0,05 ; * * \mathrm{p}<0,01$

\section{Araştırma Sonuçları ve Tartışma}

\subsection{Genel Değerlendirme}

Araştırma çerçevesinde öne atılan hipotezlerin sonuçları ve sonuçlara ilişkin değerlendirmeler bu bölümde ele alınacaktır.

H1.1: Güvenlik performansı değişkenlerinden çalışanların güvenli davranışları değişkeni ile her bir güvenlik kültürü değişkeni arasında istatistiksel olarak anlamlı bir farklılık var mı?
Güvenlik performansı değişkenlerinden çalışanların güvenli davranışları değişkeni ile her bir güvenlik kültürü değişkeninin birbirleri aralarındaki ilişkinin istatistiksel olarak anlamlı bulunduğunu söyleyebiliriz. Güvenli performans değişkenlerinden güvenli davranış değişkeni ile her bir güvenlik kültürü değişkeninin birbirleri üzerinde nasıl bir etkiye sahip olduğunu anlamak için korelasyon analizi yapıldı. Gerçekleştirilen istatistiksel analizin neticesinde, kadercilik ve güvenlik önceliği dışındaki diğer bütün boyutlarla pozitif yönde istatistiksel olarak anlamlı bir ilişki olduğunu söyleyebiliriz. 
Güvenlik performansı değişkenlerinden güvenli davranış değişkenini güvenlik kültürü değişkenlerinden güvenlik farkındalığı ve yetkinlik değişkeni ile en fazla etkileşim içinde olan değişkenlerdir $(\mathrm{r}=, 684 ; \mathrm{p}<0,01)$. Katılımcıların iş güvenliğine ilişkin bilinçli olmaları, çalıştıkları alanda gördükleri riskleri sorumlulara bildirmek, iş güvenliğine ilişkin çalışmaları desteklemek gibi iş sağlığı ve güvenliğini destekleyecek çalışmalara katılmaları işlerini yaptıkları esnada güvenli davranış sergilemelerini sağlamaktadır.

H2.1: Demografik veri değişkenlerinden medeni durum değişkeni ile her bir güvenlik kültürü değişkenleri istatistiksel olarak anlamlı bir farklılık var mı?

Güvenlik kültürü değişkenlerinin demografik değişkenlerden medeni durum değişkeni ile birbirleri üzerindeki etkiye baktığımızda aralarındaki ilişkinin istatistiksel olarak anlamlı bulunmadığını söyleyebiliriz ( $\mathrm{p}>0,05)$. Kadercilik dışındaki diğer değişkenlerinin ortalamalarının evli olan katılımcıların daha fazla olduğunu söyleyebiliriz. Buna göre, "demografik değişkenlerden medeni durum değişkeni ile her bir güvenlik kültürü değişkenlerinin birbirleri arasındaki ilişkinin ilişkinin istatistiksel olarak anlamlı bulunduğunu söyleyebiliriz. Dolayısıyla ikinci hipotez reddedilmiştir.

H3.1: Güvenlik kültürü alg1 düzeyleri cinsiyet değişkeni ele alındığında cinsiyet bakımından çalışanların alg1 düzeyleri arasında istatistiksel olarak anlamlı bir farkl1lık var mı?

Güvenlik kültürü değişkenlerinin, cinsiyet değişkeni ile ilişkisine baktığımızda, kadın çalışanların güvenlik kültürü değişkenlerine göre ortalamaları, kadercilik değişkeni hariç diğer her bir boyutta erkek işçilere göre daha yüksek olarak tespit edilmiştir. Buna göre, ele alınan güvenlik kültürü değişkenleri açısından kadın ve erkek değişkenleri baz alındığında aralarında istatistiksel olarak farklılıklar olmadığı söylenebilir $(\mathrm{p}>0,05)$. Buna göre, güvenlik kültürü değişkenleri içerisinde yer alan herbir boyut açısından üçüncü hipotez reddedilmiştir.

H4.1: Güvenlik kültürü değişkenlerinden yaş grubu boyutu ile her bir güvenlik kültürü değişkenleri arasında istatistiksel olarak anlamlı bir farklılık var mı?

Buna göre, ele alınan güvenlik kültürü değişkenleri ile (raporlama kültürü değişkeni hariç) yaş aralığı değişkenleri aralarında istatistiksel olarak $\% 5$ anlamlılık düzeyinde farklılık bulunmadığı söylenebilir ( $>>0,05)$. Raporlama kültürü ile yaş aralığı değişkenlerinin birbiri aralarında istatistiksel olarak \%5 anlamlılık düzeyinde farklılık bulunmadığı söylenebilir $(\mathrm{p}<0,05)$. 30-39 yaşları aralığında bulunanlar fazla raporlama kültürüne sahiptir.

H5.1: Demografik değişkenlerden öğrenim seviyesi değişkeninin her bir güvenlik kültürü değişkenleri arasında istatistiksel olarak anlamlı bir farklılık var mı?

Çalışanların öğrenim seviyesi değişkeni ile herbir güvenlik kültürü değişkenlerinin birbiri arasındaki ilişkinin istatistiksel olarak \%5 anlamlılık düzeyinde farklılık bulunmadığ söylenebilir ( $p>0,05)$. Dolayısıyla beşinci hipotez bütün boyut değişkenleri açısından reddedilmiştir.

H6.1: Demografik değişkenlerden işletmedeki konumu değişkeni ile her bir güvenlik kültürü değişkeni arasında istatistiksel olarak anlamlı bir farklılık var mı?

Çalışanların işteki konumlarına göre güvenlik kültürü değişkenleri ortalamalarını göstermektedir. Buna göre, yöneticilik konumunda çalışanların, raporlama kültürü, yönetimin bağlılı̆̆ı, güvenlik farkındalığı yetkinliği ve güvenlik iletişimi ve eğitimi düzeylerinin, diğer düzeydeki çalışan katılımcıların algılarından fazla olması dikkati çekmektedir. Diğer taraftan, kadercilik, çalışanların katılımı ve güvenlik önceliği değişkenleri açısından baktığımızda ise, çalışanların tüm bu boyutlardaki algılarının, yönetici olarak çalışanların algılarından daha yüksek olduğu görülmektedir. Yapılan çalışmada, katılımcıların işletmedeki pozisyonuna göre bütün boyutlar için istatistiksel olarak \%5 anlamlılık düzeyinde farklılıklar bulunmadı̆̆ söylenebilir ( $>00,05)$. Dolayısıyla altıncı hipotez reddedilmiştir.

H7.1: Çalışma hayatında iş kazasına uğrama ile her bir güvenlik kültürü değişkeni arasında istatistiksel olarak anlamlı bir farklılık var mi?

Çalışma yaşamında iş kazası geçiren çalışanların raporlama kültürü, çalışanların katılımı, güvenlik iletişimi ve eğitimi ortalamaları, maruz kalmayan çalışanlardan daha düşük olduğu görülmektedir. Yapılan çalışmada güvenlik kültürü boyutları ile iş yaşantısında iş kazasına uğrama değişkenlerinin birbiri üzerindeki etkisine bakıldığında aralarında $\% 5$ anlamlılık düzeyinde farklılık bulunmadığı söylenebilir $(\mathrm{p}>0,05)$. Bu bulgular 1şığında, çalışmada ileri sürülen yedinci hipotez bütün boyut değişkenleri açısından reddedilmiştir.

H8.1: Mevcut iş yerinde İş kazasına maruz kalanlar ile maruz kalmayanlar arasında istatistiksel olarak 'güvenlik farkındalığı ve yetkinliği, çalışanların katılımı ve kadercilik' boyutlarında anlamlı farklılıklar var mı?

Mevcut iş yerinde kazaya uğrayan katılımcıların ortalamaları iş kazasına uğramayan çalışanların ortalamalarından; çalışanların katılımı, kadercilik, raporlama kültürü, yönetimin bağlılığ1, güvenlik iletişimi, güvenlik önceliği ve güvenlik eğitimi değişkenleri daha yüksektir. Ölçek verilerine göre, iş kazasına maruz kalma ile herbir güvenlik kültürü boyutu bakımından aralarında $\% 5$ anlamlılık düzeyinde farklılık bulunmadığ söylenebilir $(\mathrm{p}>0,05) . \mathrm{Bu}$ bulgular 1şı̆̆ında, çalışmada ileri sürülen sekizinci hipotez bütün boyut değişkenleri açısından reddedilmiştir.

H9.1: Güvenlik kültürü değişkenlerinden güvenlik eğitimi değişkeni ile güvenlik performansı değişkenlerinden güvenli davranış değişkeni arasında istatistiksel olarak anlamlı bir farklılık var mi?

Güvenlik kültürü ve güvenlik performansı değişkenlerinin birbirleri üzerinde nasıl bir etkiye sahip olduğunu anlamak için korelasyon analizi yapılmıştır. Güvenlik eğitimi değişkeni ile güvenli davranış değişkeninin birbiri arasındaki ilişkinin istatistiksel olarak da anlamlı bulunduğu söylenebilir. Güvenlik eğitimindeki olumlu artışlar, çalışanların güvenli davranış gösterme eğilimlerini arttırmaktadır. Dolayısıyla dokuzuncu hipotez kabul edilmiştir.

\section{Sonuç ve Öneriler}

$\mathrm{Bu}$ araştırma kapsamında, literatür çalışmalarından edinilen çıkarımlar doğrultusunda belirlenen anket veri toplama aracı olarak kullanılmıştır. Araştırmanın Türkiye'de Marmara bölgesinde Elektrik ve Elektronik üretim endüstrisinde çalışan beyaz yakalı çalışanlara uygulanmasına karar verilmiştir. Araştırmada kullanılan ölçeklerden elde edilen verilerin istatistiksel analizleri gerçekleştirilmiştir. Böylece, firmaların Dünya Klasmanında Üretimin pillar' ından olan Dünya Klasmanında İş Sağlığı ve Güvenliği seviyeleri; güvenlik kültürü, liderlik, güvenlik planı ve güvenlik performansı ve bunların bir fonksiyonu olarak açıklanmaya çalışılmıştır. Verilerin analiz sonuçları üzerinden, güvenlik kültürüne, liderliğine, güvenlik planı üzerinde etkiye sahip olan boyutlar saptanarak güvenlik performansı üzerindeki etkisi hesaplanmaya çalışılmıştır.

$\mathrm{Bu}$ konular üzerinde yürütülen çalışmalardan elde edilen çıkarımlar doğrultusunda, güvenlik kültürü son zamanlarda iş 
kazalarını önlemede kullanılan önemli bir kavramdır. Bu kavram, sağlık ve güvenlik unsurlarının öncelikli olarak değerlendirildiği çalışma ortamları oluşturulması hususunda büyük bir öneme sahip olduğu bilinmektedir. $\mathrm{Bu}$ hususta yöneticilere birtakım sorumluluklar düşmektedir. Bunlar, çalışma ortamının güvenli hale getirilmesine, organizasyonda çalışanların güvenlik kültürü algı düzeylerini pozitif yönde oluşturmasına katkıda bulunmak ve bu anlamda her faaliyeti destekleyici davranışlarda bulunmak ve DKG algı düzeylerini iyileştirici uygulamaları teşfik etmektir.

Araştırma bulguları, güvenlik performansı değişkenleri ile herbir güvenlik kültürü değişkeni bakımından istatistiksel olarak anlamlı bir farkın olduğu söylenebilir. Aynı zamanda, demografik değişkenler ile her bir güvenlik kültürü değişkeni arasında istatistiksel olarak anlamlı ilişkiler saptanmıştır.

$\mathrm{Bu}$ araştırmada birtakım sınırlar konulmuştur. Bu çalışmada, güvenlik performansı değişkenlerinden olan güvenli davranış değişkeni ile her bir güvenlik kültürü değişkenleri arasındaki ilişkiler incelenmiştir. Bu alanda yürütülen başka çalışmaların sonuçlarından yola çıkarak, güvenli davranış boyutunu etkileyen başka değişkenlerin de olduğu söylenebilir. Bu çalışma, bundan sonraki yürütülecek araştırmaların güvenlik kültürü dışındaki güvenlik planı ve liderlik gibi diğer değişkenlerle güvenlik performansı değişkenlerinden güvenli davranış değişkeni arasındaki ilişkiyi anlamaya yönelik çalışmaların olmasına gereksinim duyulduğunu göstermektedir. Önümüzdeki süreçte, her bir organizasyondaki ayrılıkları gözler önüne sermek için, farklı sektörlerde belirli periyotlarda tekrar edecek araştırmaların gerçekleştirilmesine ihtiyaç duyulmakta olduğu söylenebilir. Böylece, belirli bir süreç sonrasında gözlenen değişim konusunda fikir sahibi olunabilir.

\section{Teșekkür}

$\mathrm{Bu}$ araştırmaya katılmayı kabul eden firmalara ve araştırma kapsamında uygulanan ölçeklere yanıt vererek katkı sağlayan firma çalışanlarına teşekkürlerimizi sunarız.

\section{Kaynakça}

Aytaç, S. (2011), “İş kazalarını önlemede güvenlik kültürünün önemi”, Türk Metal Dergisi, Sayı:147-148, ss.30-33 / ss.3639.

Bergersen C. (2003). Tool To Be Used To Survey and Improve Safety Culture In The European Railway Industry. Faculty of Social Sciences and Technology Management, Department of industrial Economics and Technology Management, NTNU, Trondheim, Norway (Colleboration with SINTEF).

Boroughf B.J. (2012). An Examınation Of The Relationship Between Transformational Leadershıp Tendencies And Safety Outcomes In Selected Manufacturing Settings. Indiana State University, College of Technology, Terre Haute, Indiana.

Bozağaç İ. (2010). World Class Manufacturing on Automobile Industry and Applications of Autonomous Maintenance in Press Shop. Çukurova Üniversitesi, Department Of Mechanichal Engineering, Adana.

Büyüköztürk, Ş. (2018). Sosyal Bilimler için Veri Analizi El Kitab1. Pegem Akademi, Ankara.

Caravello, H. E. (2011). The role o f leadership in safety performance and results (Doctoral dissertation). Available from Proquest Dissertations and Theses database. (UMI 3444344)
Carlo F.D. and Simioli G.R. (2018). Lean Production and World Class Manufacturing: A Comparative Study of the Two Most Important Production Strategies of Recent Times. University of Florence, Department of Industrial Engineering, Filippo De Carlo, Italy.

Cox, S.J., \& Cheyne, A.J.T. (2000). Assessing Safety Culture in Offshore Environments. Safety Science Journal, 34, 111-129.

Çögenli, M.Z ve Özer, M. (2017). İş kazalarını önlemede güvenlik kültürü. 2nd International Congress on Political, Economic and Social Studies (ICPESS), 19-22.

Cuevas, A. ve Febrero, M. ve Fraiman, R. (2004). Fonksiyonel Veriler İçin Bir Anova Testi. Hesaplamalı İstatistikler ve Veri Analizi, 111-122.

Dursun S. (2011). Güvenlik Kültürünün Güvenlik Performans1 Üzerine Etkisine Yönelik Bir Uygulama. Uludağ Üniversitesi, Sosyal Bilimler Enstitüsü, Çalışma Ekonomisi Ve Endüstri İlişkileri Anabilim Dalı Yönetim Ve Çalışma Psikolojisi Bilim Dalı, Doktora Tezi, Bursa.

Dursun S. (2013). İş Güvenliği Kültürünün Çalışanların Güvenli Davranışları Üzerine Etkisi. Karadeniz Teknik Üniversitesi, Ekonomisi ve Endüstri İlişkileri Bölümü, Trabzon.

Geçgil E. (2018). Dünya Sınıfında İmalat Kavramı ve bir Lojistik Uygulaması. Uludağ Üniversitesi, Sosyal Bilimler Enstitüsü, Ekonometri Anabilim Dalı, Yöneylem Bilim Dalı, Doktora Tezi, Bursa.

Gürbüz H. and İbrakoviç H. (2017). İşletmelerde İş Güvenliği, Güvenlik Performansı ve İş Güvenliği Kültürü. The journal of Social Science, 4, 11, 442-469.

Kim, T.K. (2015). Parametrik İstatistik Olarak T Testi. Kore Anesteziyoloji Dergisi, 540-546.

McHugh, M.L. (2013). Ki-Kare Bağımsızlık Testi. Biochemia Medica.

Pallant, J. (2017). SPSS Kullanma Kilavuzu: SPSS ile Adım Adım Veri Analizi. Anı Yayıncılık, Ankara.

Seyedhosseini M.S. and Soloukdar A. (2011). Recognition Dynamic Model of World Class Manufacturing in Iranian Automotive Industry. Australian Journal of Basic and Applied Sciences, 5, 9, 182-189.

Ingle S. (1999). World Class Manufacturing: Implementation and Measurement in the Irish Automotive Rubber Mouldings Component Industry. Dublin City University Business School, PhD Thesis.

Kol İ. (2016). İş Sağlığı Ve Güvenliğinde Operasyonel Disiplin. Gedik Üniversitesi, Sosyal Bilimler Enstitüsü, İş Sağlığı Ve Güvenliği Yüksek Lisans Programı, Master Tezi, İstanbul.

Kurtulmuş, G. (2019). Comparison of Safety Culture Perceptions of University Student Groups. Middle East Technical University, The Graduate School of Natural And Applied Sciences, Master Thesis, Middle East Technical University.

Olcay, Z. (2021). İş Sağlığı ve Güvenliğgi Kültürü Ölçeği; Geçerlik ve Güvenirlik Çalışması. Avrupa Bilim ve Teknoloji Dergisi, (23), 678-685

Olcay Z.F., Temur S., ve Sakalli A.E. (2021a). A research on the knowledge level and safety culture of students taking occupational health and safety course. Cypriot Journal of Educational Sciences, 16, 1, 187-200.

Olcay Z.F., Temur S., Sakalli A.E. ve Yazici A. (2021b). A study on the shift in fatal construction workrelated accidents during the years 2012-2019 in Turkey. International Journal of Occupational Safety and Ergonomics, pp.1-11.

Öztürk T. (2020). Giyim Eşyası İmalat Sektöründe Meydana Gelen İş Kazası ve Meslek Hastalığı ile Sonrasındaki İyileşme Durumunun Cinsiyet Bakımından 
Değerlendirilmesi. Busıness \& Management Studıes: An International Journal, 8, 3 3424-3443.

Öztürk T. ve Eren Ö. (2019). Yaralanmalı İş Kazalarının En Fazla Meydana Geldiği İlk Otuz Sektörün Entropi Tabanlı Sıralama Tekniği İle Ayrıntılı İncelenmesi. Busıness \& Management Studies: An International Journal, 71 153-171.

Öztürk T. ve Akın G. (2021). Türkiye' de Tüm Sektörlere Ait 2018 Yılı İş Kazalarının ve Kaza Sonucu Yaşam Kaybının Kazazede Yaşı Bakımından Değerlendirilmesi. Avrupa Bilim ve Teknoloji Dergisi, 22, 410-415.

Jahanzaib M. (2008). Coping with Medium Volume- Low Variety Manufacturing Environment in Automobile Industry of Pakistan. University of Enginnering and Technology, Department of Mechanical Engineering. Faculty of Mechanical \&Aeronautical Engineering, Taxila, Pakistan.

Sakall, A. E. (2019). A Tipi Ve B Tipi Kişilik Özelliğine Sahip Bireylerde İş Doyumu Ve Kazalanma Arasındaki İlişsinin İncelenmesi. Ohs Academy, 2(1), 11-31.

Sayıc1 F., \& Öztürk T. (2020). Türkiye'de 2019'da Gösterime Girmiş Filmlerin Sosyal Gereklilik Ve Sektör Ekonomisi Bakımından İncelenmesi. Busıness \& Management Studies: An International Journal, 8, 5, 4413-4437.

Temur, S. (2019). Türkiye Ve Çekya Arasındaki Güvenlik Kültürüne Bakış Açısı Üzerine İrdeleme. Ohs Academy, 2(2), 67-76.

Tepekule E.T. (2015). Dünya Klasmanında Üretim Kapsamında İş Sağlığı Ve Güvenliği Çalışmalarına Yönelik Bir Model Önerisi Ve Uygulama. Dokuz Eylül Üniversitesi, Sosyal Bilimler Enstitüsü, İşletme Anabilimdalı, İşletme Programı, İzmir.

Zopçuk O. (2015). İşletmelerde Güvenlik Kültürünün Ölçümü: Küçük Ve Büyük Ölçekli Tekstil Ve Metal İşyerleri Uygulaması. Çalışma Ve Sosyal Güvenlik Bakanlığı, İş Sağllğı Ve Güvenliği Genel Müdürlüğü, İş Sağllğı Ve Güvenliği Uzmanlık Tezi, Ankara. 